\title{
PRESSUPOSTOS TEÓRICO-PEDAGÓGICOS DA INICIAÇÃO RÍTMICA NAS AULAS DE DANÇA
}

\author{
N.V. PINTO' ${ }^{1}$, P.R.F. LIMA \\ Instituto Federal de Educação, Ciência e Tecnologia do Ceará \\ nvp.ifce@gmail.com ${ }^{1}$
}

Artigo submetido em 06/04/2017 e aceito em 07/08/2019

DOI: $10.15628 /$ holos.2019.5866

\section{RESUMO}

A formação educativa do aluno de dança deve ser constituída da aprendizagem dos elementos rítmicos advindos das inúmeras experiências vivenciadas em aula. O percurso metodológico no ensino do ritmo comumente empregado se baseia na contagem musical e mensuração quantitativa de seus constituintes. Todavia, a ampla exploração de estratégias sensório-motoras pode fortalecer a aprendizagem rítmica. A partir dessas reflexões, este artigo tem como objetivo discutir alguns pressupostos teóricos no estudo do ritmo inseridos nas perspectivas pedagógicas de iniciação rítmica nas aulas de dança.

PALAVRAS-CHAVE: Ritmo, Dança, Iniciação Rítmica.

\section{SOCIODEMOGRAPHIC AND HEALTH CHARACTERISTICS OF DIABETIC AND/OR HYPERTENSION PATIENTS}

\begin{abstract}
The training of the dance students must comprise the learning of rhythmic elements from the numerous class experiences. The methodological approach on rhythmic teaching, usually employed, is based on the musical score and quantitative measurement of its constituents. But, also, the broad exploitation of sensory-motor strategies
\end{abstract}

can strengthen the rhythmic learning. Thus, considering these reflections, this article aims to examine some theoretical assumptions of the rhythm study for future considerations in pedagogical procedures of rhythmic initiation into dance classes.

KEYWORDS: Rhythm, Dance, Rhythmic Initiation. 


\section{INTRODUÇÃO}

Entre os inúmeros elementos constituintes da dança, o ritmo é um componente inerente à sua ação e capaz de ampliar a práxis docente e discente. Sua abordagem didático-pedagógica deve compor uma das estratégias iniciais da formação rítmica do aluno em iniciação à dança.

Em verdade, os elementos rítmicos estão presentes no cotidiano e ampliam as experiências sensório-motoras, com isso, fortalecendo as interseções entre o ambiente intrínseco e extrínseco. A exploração rítmica mediante vivências motoras, seja na infância ou na fase adulta, fomenta relações neurofuncionais e promove a sensibilidade equalizada e necessária para a aprendizagem técnica da dança.

A busca por estratégias de aprendizagem rítmica deve ultrapassar o senso comum, pelo qual esse caminhar é limitado pelos sons da música como a única ferramenta de ensino e aprendizagem, e permitir o desvelo de novas possibilidades sensoriais. A ação didática no ensino do ritmo nas aulas de dança deve ser composta pelas inúmeras formas de exploração das sensações somáticas (tato e proprioceptivas) e especiais (olfato, gustação, visão, audição e equilíbrio), garantindo ao aluno uma ampla oportunidade de associações sensório-motoras e consequente refinamento técnico do movimento.

Conforme o exposto, este artigo discute pressupostos teóricos e pedagógicos que conduzem a reflexão em torno do aprendizado rítmico nas aulas de dança. Traz, ainda, uma fundamentação conceitual sobre o estudo do ritmo, considera as interseções neurofisiológicas do

trato rítmico e, em adição, junto a algumas contribuições de educadores musicais, fornece perspectivas didáticas para o ensino do ritmo nas aulas de dança.

Trata-se de uma abordagem construída pelos autores a partir de reflexões e elaborações didáticas no ensino da rítmica em cursos de extensão, graduação e pós-graduação nas áreas de Dança e Educação Física. Sua gênese surgiu a partir dos anseios e das expectativas dos discentes no vislumbre da ação pedagógica futura.

\section{FUNDAMENTOS CONCEITUAIS PARA O ESTUDO DO RITMO}


O reconhecimento do ritmo inserido na dança perpassa por sua essência conceitual. Monteiro e Artaxo (2003) descrevem o ritmo como o elemento humano básico nas manifestações da vida. Sua origem etimológica vem do grego "rhythmos", designando tudo aquilo que flui ou tenha movimento regulado. Le Boulch (apud CAMARGO, 1994) refere-se a uma estruturação de fenômenos que se desenvolve ao longo de um tempo.

Esses conceitos direcionam para o entendimento de que o ritmo está presente em toda ação que apresente elementos repetitivos, contínuos e regulares. Numa reflexão biológica, podese exemplificar o ritmo dos batimentos cardíacos, em que a sístole (contração miocárdica) e a diástole (relaxamento miocárdico) representam os componentes desse ritmo, uma vez que apresentam características de fluência, continuidade e repetição ao longo de um tempo.

Na dança, entre os inúmeros elementos rítmicos presentes, a música, por ser constituída de pulsos fortes e fracos, instrumentos e vocais, contínuos e regulares, ao longo de um tempo, torna-se uma excelente representação do ritmo. Embora seja reconhecido por seu aspecto motivacional, o domínio métrico desses elementos constitutivos da música fornece uma ferramenta de ampla ação didático-pedagógica.

Para isso, há de se perceber que esses elementos, ao se mostrarem repetitivos e regulares, podem ser mensurados e, portanto, quantificados para uma ampla ação didática na dança, quer seja na contagem musical para uma execução rítmica, quer seja na elaboração coreográfica metrificada.

Este domínio métrico da música (especialmente a contagem do pulso forte), além de fomentar a motivação do bailarino, será capaz de facilitar a aprendizagem motora, reforçar a memória, ampliar a criatividade e auxiliar na incorporação dos elementos técnicos da dança.

Nessa perspectiva, Caregnato (2011) afirma que a estratégia inicial para o ensino do ritmo deve se basear na subdivisão do pulso em unidades mensuráveis, sendo esta metodologia a mais adequada na aprendizagem rítmica, especialmente ligada à educação musical. Didaticamente, o ritmo passa a ser algo objetivo e contável pelo professor. É sensato perceber que tal método de ensino é mais adequado a alunos que já tenham maturidade com a contagem numérica, uma vez que se trata de uma abordagem metrificada. 
Todavia, não se pode deixar de apreciar, neste contexto, a estratégia mnemônica, muito utilizada pelos músicos na educação rítmica infantil. Trata-se de um método de ensino direcionado à associação de palavras a motivos ou a pequenos grupos de elementos musicados, facilitando, desse modo, a memorização de uma sequência de notas dentro de um repertório musical. Como exemplo, pode-se associar a palavra "música" a uma colcheia e duas semicolcheias, substituindo a contagem musical pela associação de palavras aos elementos rítmicos.

Muitos educadores musicais adotam a metodologia mnemônica na educação rítmica das crianças por facilitar, de maneira lúdica, a aprendizagem das células rítmicas, muito embora não seja apreciada pelos educadores mais conservadores.

A escolha entre o método métrico ou o mnemônico advém da maturidade numérica do aluno. Ambas representam estratégias potencialmente positivas na aprendizagem do ritmo e podem ser utilizadas tanto nas aulas de educação musical quanto nas aulas de dança. Entretanto, é preciso considerar a necessidade de utilização da metodologia metrificada nas aulas de dança, nas quais a inserção técnica dos movimentos esteja presente. Assim, sua abordagem deve compor o percurso didático no estudo introdutório do ritmo, a fim de facilitar os futuros procedimentos didáticos na iniciação técnica dos movimentos nas aulas de dança.

\section{ASPECTOS NEUROFISIOLÓGICOS DA APRENDIZAGEM RÍTMICA}

O conhecimento e o aprimoramento da métrica musical, decisivos na ação rítmica do bailarino, necessitam da ampliação de estímulos sensoriais e consequente integração desses inputs no sistema nervoso central para que seja possível a coordenação dessa métrica com o movimento.

Esse processo neurofisiológico é iniciado a partir dos inúmeros estímulos sensoriais aos quais o aluno/bailarino deve ser apresentado, desde relações somáticas, como os estímulos proprioceptivos de espaço, tensão, relaxamento e amplitude de movimento, até os sentidos especiais, como a visão e a audição. Para o bailarino, o processo de aprendizagem motora é composto especialmente pelo somatório de estímulos visuais, que identificam o movimento, estímulos auditivos, que ampliam essa identificação por meio do ato verbal do professor e da métrica musical, e cinestésico ao concretizar o ato pedagógico pela experiência motora de contato. 
Assim, a exploração do ritmo enquanto elemento básico na aprendizagem motora não deve se limitar apenas a dinâmicas que ofertem estímulos auditivos, e, sim, ser fomentada pelo maior número possível de estímulos (somáticos e especiais). Sua aprendizagem rítmica será dependente desses processos sensoriais periféricos para que, ao se associarem às estruturas centrais, possam promover respostas motoras de excelência.

Tortora e Derrickson (2016) afirmam que a aprendizagem necessita produzir alterações funcionais persistentes advindas das experiências sensoriais que, quando combinadas, promovam a plasticidade no sistema nervoso - esta conceituada como a capacidade de alterar o comportamento em resposta aos diferentes estímulos, sejam internos ou externos. As diferentes experiências sensoriais podem promover alterações em neurônios individuais, como a ampliação dendrítica (principal região receptora da informação) e a síntese de novos receptores de membrana, ampliando desta forma as conexões sinápticas neuronais e, consequentemente, a resposta motora.

A construção do movimento associado ao ritmo não é algo que possa ser aprendido apenas de forma extrínseca, sendo necessária a combinação dos elementos rítmicos externos e internos que, quando coordenados, ativam, associam e consolidam as relações psicomotoras. Assim, como mencionado anteriormente, a música, por ter elementos repetitivos e variados, promove, além da motivação, o alicerce educativo na inter-relação entre o ambiente interno e externo para o processo de cognição musical e, consequentemente, a aprendizagem motora rítmica (JUNQUEIRA; FORNARI, 2015).

As diferentes experiências sensoriais promovidas no ato didático do ensino rítmico estimulam o sistema nervoso periférico a conduzir, via aferente, essas relações para áreas de controle encefálico, como as áreas associativas dos lobos frontais, parietais, occipitais e temporais, partes do sistema límbico e diencéfalo, bem como áreas primárias somatossensoriais e motoras. A integração central das diversas sensações possibilitará a plasticidade neural necessária para efetivar a ação motora. O movimento, determinado pela resposta somática às estruturas musculares, é modulado quanto à intensidade, amplitude e tensão pelas relações proprioceptivas e quanto ao equilíbrio e refinamento do gesto pelo cerebelo, núcleos da base e áreas do córtex motor (TORTORA; DERRICKSON, 2016). 
Cordero (2014) comenta que o desenvolvimento motor na infância é iniciado pelos movimentos reflexos, caracterizados pelas ações involuntárias de domínio autonômico, até chegar ao desempenho das habilidades motoras básicas desenvolvidas por meio da exploração do ambiente em que a criança vive. Dessa forma, o aprimoramento das atividades motoras básicas é decorrente da vasta exploração sensorial de seus praticantes.

Laban (apud MOTA, 2012) retrata que o ritmo é constituído de elementos como a velocidade, fluidez, intensidade e tamanho, que, quando combinados, determinam a variação do movimento. Para o autor, o movimento é algo universal, presente em todos os seres vivos e motivado pelas necessidades básicas, como a locomoção e as relações sociais e emocionais. Nesse sentido, a motricidade humana é um produto da combinação de elementos rítmicos que envolvem relações sensório-motoras para fins de suprir necessidades básicas do ser humano.

Sob tal perspectiva, há de comungar-se com a proposta didático-pedagógica descrita nos Parâmetros Curriculares Nacionais da Educação Física (BRASIL, 1997) para as atividades rítmicas e expressivas no ensino fundamental, que caracteriza seu bloco de conteúdos com intenções de expressão e comunicação a partir de gestos (estímulos visuais e cinestésicos) e estímulos sonoros (auditivos) pela dança (brasileira, urbana, erudita, etc.) associada às manifestações musicais, lengalengas, brincadeiras de rodas, cirandas e brinquedos cantados.

Os Parâmetros Curriculares do Ensino Médio (BRASIL, 1999) propõem a inclusão de conteúdos alicerçada nas linguagens verbal, não verbal e digital a partir da experiência de articulação e integração destas, como, por exemplo, a gênese de novas poéticas que articulem imagens, sons e animações advindas de recursos tecnológicos (videoclipes, jogos interativos, trabalhos artísticos em CD ROM) e acrescenta que construções simbólicas são resultantes das possibilidades de articulação dos signos artísticos (visual, sonoro e corporal) e das motivações (sociais, culturais, psicológicas, científicas, entre outras), o que caracteriza, novamente, a diversidade de estímulos sensoriais como uma estratégia pedagógica de ampliação das habilidades e competências da dança.

\section{CONTRIBUIÇÕES TEÓRICAS PARA O ESTUDO DA RÍTMICA}


O processo de ensino-aprendizagem da rítmica corporal e musical vem sendo discutido e explorado por diversos cientistas da arte. Neste estudo, são discutidas as contribuições metodológicas de Dalcroze, Willems e Orff com o intuito de nortear estratégias didáticopedagógicas para o ensino do ritmo nas aulas de dança.

Émile Jaques-Dalcroze direcionou seu método de educação musical na exploração das vivências corporais em busca do desempenho sensório-motor e consequente projeção técnica e emocional. Suas pesquisas o levaram a desenvolver o método Eurrítmico - baseado na dinâmica corporal associada à sensibilidade perceptiva de distinção dos elementos musicais (pulsos, compassos, frases, entre outros). Afirmava, então, que todos os elementos da música podem ser experimentados (vivenciados) por meio do movimento, em que o corpo, que faz os sons, é o primeiro instrumento musical a ser treinado. Ampliando a dinâmica corporal e o estudo musical com a diferenciação de gestos para cada som (acentuação, pulso, andamento, métrica).

Dalcroze colocou que o ritmo musical seguia em paralelo ao ritmo da vida, presente antes mesmo do nascimento, como na dinâmica cardiovascular fetal, e desenvolve-se inconscientemente nos primeiros anos de vida com as descobertas e experiências em tudo que se faz, vê e ouve, nas quais o uso do corpo no conhecimento rítmico musical é capaz de proporcionar uma educação múltipla, ampliando, assim, as relações psicomotoras e a criatividade.

Esse educador musical mostrou a necessária interação entre os estímulos intrínsecos e extrínsecos na aprendizagem rítmica, estabelecendo relações entre a "alma e o cérebro" (como postulava) através de um ato educativo com base nos estímulos sensoriais, especialmente auditivos, e na atuação do corpo enquanto instrumento.

Vale ressaltar que a Eurritmia, desenvolvida por Dalcroze, refere-se a movimentos improvisados pelos alunos com o intuito de ampliar a musicalidade e não com pressupostos técnicos e aplicações coreográficas. Trata-se de uma abordagem metodológica que deve ser desenvolvida mediante a expressão pessoal de cada executante, possibilitando a expressão plena do que este está ouvindo.

Numa perspectiva cinestésica inspirada na Eurritmia, Dalcrozeana, Greenhead e Habron (2015) discutem uma prática somática, pelo contato corporal, como uma linha exploratória nas associações entre a música, o movimento e a improvisação. Para esses autores, o contato corporal, 
aliado à improvisação eurrítmica, gera uma afinação psicomotora reconhecida pelo sentir, pensar e fazer com mais acuidade.

Esses autores trazem uma proposta educativa cujo foco está na investigação da natureza háptica da visão e do som, utilizando-se de práticas como as marchas e corridas em duplas ou conjuntos, ampliando o contato corporal, o uso de percussão corporal e a manipulação de materiais e instrumentos que possam, de maneira improvisada, desenvolver células ritmadas.

Edgar Willems, assim como Dalcroze, desenvolveu sua abordagem metodológica a partir das vivências corporais e da sonoridade inata do ser humano. Um método capaz de integrar as relações psicomotoras através da vivência corporal musicada antes do ensino da teoria musical, devendo a ação docente partir de elementos naturais do ser humano, tais como marchas, saltos e movimentos giratórios.

Willems elaborou uma abordagem pedagógica segmentada em graduações por faixa etária, muito embora a maturidade musical dos alunos pudesse se sobrepor às relações cronológicas. Assim, sistematizava o emprego de movimentos corporais do cotidiano em relação à maturidade do aluno a fim de despertar reações emotivas a partir de movimentos que são instintivos, como alterações respiratórias resultantes de variações da marcha aliadas à música.

Abordagens rítmicas de caráter espontâneo, que explorem a natureza das habilidades motoras básicas, desenvolvem a psicomotricidade e a capacidade volitiva de seu praticante. Assim, há de perceber que a aprendizagem rítmica está atrelada ao desempenho sensório-motor, desenvolvida a partir de vivências motoras básicas que devem compor a sistemática inicial de qualquer ação didático-pedagógica na dança, independente dos aspectos cronológicos, e pela maturidade psicomotora entre a música e o movimento.

A educação musical na infância também foi abordada por Carl Orff. Seu método se alicerçava na imaginação melódica das crianças, em que todos são participantes e não apenas ouvintes. Seus procedimentos didáticos eram desenvolvidos mediante atividades lúdicas como o cantar, rimar e o percutir de poemas, provérbios, jogos e canções, servindo como elementos de suporte para acompanhamento palmas, batidas com os pés, baquetas ou com qualquer objeto que estivesse à mão. 
Tratava-se de uma abordagem metodológica destinada a todas as crianças, não buscando os talentos privilegiados, mas a contribuição de cada praticante a partir de suas habilidades individuais. Na sua prática educativa, não havia a necessidade de conhecimento musical prévio, uma vez que os sons e os gestos corporais promoviam a expressão do ritmo, tendo a voz como o primeiro e mais natural dos instrumentos.

Nessa ação pedagógica também havia a participação de instrumentos especiais, como xilofones de madeira e glockenspiels - que oferecem como atrativo a facilidade de se controlar as notas disponíveis (ao remover uma ou mais placas) e a produção imediata do som. Os tambores, em toda a sua vasta gama de tamanhos, formas e sons, também, eram constituintes dessa ação. Orff utilizava ainda o ostinato (padrão rítmico, falado ou cantado, que se repete) como elemento que dava forma às improvisações.

Assim, na metodologia de Orff, o ensino da rítmica advém da exploração corporal (utilizando o corpo como um instrumento de percussão), vocal (explorando a palavra em todas as suas potencialidades) e do uso de instrumentos com ênfase em exercício de criação e improvisação.

A partir desses pressupostos, a estratégia didática de iniciação rítmica deve familiarizar os alunos com os conteúdos por meio de atos motores multissensoriais que se coordenem com sons e silêncio, música e percussão corporal, elementos vocalizados e improvisações, imitações corporais e jogos musicais com instrumentos.

Nesta interface, a aprendizagem rítmica advém da proposta de ampla aplicação sensorial, com base em exercícios e jogos que ampliem o desempenho psicomotor. Práticas educativas que se utilizem das habilidades motoras básicas, como marchar, saltar e correr, colaboram com a exploração sensório-motora, ampliando, desse modo, relações proprioceptivas, de equilíbrio e refinamento do movimento.

A percussão corporal, por sua vez, promove o desempenho da consciência corporal, lateralidade, assim como noções de espaço e tempo, importantes na assimilação do ritmo. Há de se conceber que a utilização do corpo enquanto instrumento envolve necessariamente o conhecimento sensorial, em que, pelas produções rítmicas, o aluno mostra as suas descobertas. 
Com a percussão corporal, o aluno expressa o ritmo de forma espontânea e gradativamente vai sendo conduzido a um novo ritmo proposto.

Nas dinâmicas de improvisação, por sua vez, o aluno transforma as suas inspirações e emoções em componentes criativos e expressivos. Trata-se de uma estratégia de ensino que permite formular novas ideias, explorar a diversidade de estímulos e experimentar diferentes conteúdos através do movimento. Saraiva et al. (2005) comenta que improvisar expressa o movimento próprio e espontâneo, passível de novas aprendizagens e conduções rítmicas, manifestadas com sentimento e intenção. Esses autores acrescentam que o ato de improvisar na dança, reconhecido como atividade rítmica e expressiva, aflora singularidades que transcendem o senso comum e tornam a expressão rítmica única e utilitária.

As imitações corporais corroboram os estímulos visuais na busca da ampliação do esquema corporal a partir da coordenação sensório-motora. É preciso considerar que o êxito de uma imitação resulta da articulação organizada da impressão global do movimento. $O$ gesto passa a ser comparado a todo instante e equalizado conforme é conduzido. A imitação de sons, silêncio, gestos e expressões induzem a uma coordenação perceptivo-motora, tornando as ações que, inicialmente, são cognitivas em habilidades motoras de caráter associativo e autônomo.

Por fim, mas não menos importante, os jogos musicais com instrumentos constituem uma rica estratégia de ensino, promovendo o aprendizado rítmico e o desenvolvimento psicomotor de forma lúdica e motivacional. O uso de instrumentos musicais necessitará que o aluno promova sua lateralidade e coordenação motora e desenvolva suas relações espaciais e temporais. A atenção, a memória e a linguagem podem ser estimuladas pelas ações rítmicas através dos diversos instrumentos.

Nesse caminhar, vale acrescentar as possibilidades de exploração didática com os instrumentos musicais que possam ser construídos coletivamente, propiciando o reconhecimento sensorial a partir dos diversos tipos de materiais e ampliando as experiências rítmicas por associação à diversidade de formas, tamanhos e composições desses. A ação rítmica educativa contextualizada em ambientes com multissensorialidades será capaz de ampliar as capacidades cognitivas e afetivas do aluno e torná-lo, consequentemente, mais apto à assimilação de novos conteúdos na dança. 


\section{CONSIDERAÇÕES FINAIS}

Ao reconhecer a rítmica como uma resposta à interação sensório-motora advinda da ampla variedade de estímulos sensoriais, o ato pedagógico nas aulas de dança ou mesmo nas aulas de educação musical deve ser constituído da pluralidade sensorial. Embora a música represente uma forte ferramenta motivacional, seu uso metrificado, de forma didática, promove o aprendizado rítmico com importantes interfaces pedagógicas que se fazem necessárias no percurso de aprimoramento técnico na dança. Todavia, a estratégia mnemônica pode ser utilizada na educação infantil por facilitar o reconhecimento das células rítmicas sem a necessidade de maturidade numérica.

Todo processo de ensino-aprendizagem da dança deve ser iniciado pela exploração do ritmo associada às habilidades motoras básicas, como o marchar, o correr e o saltar, em uma perspectiva natural e espontânea, com o intuito de despertar a rítmica a partir de elos intrínsecos e extrínsecos do aluno, em que a atividade rítmica será o resultado desse somatório pessoal e social.

Entre as inúmeras oportunidades metodológicas de iniciação rítmica na dança, o estudo dos elementos constituintes da música através do corpo, por intermédio de uma atitude eurrítmica, na busca pela exploração cinestésica, visual e auditiva, consolidará o aprendizado e permitirá a assimilação de novos conteúdos técnico-específicos.

O corpo, enquanto expressão rítmica natural, pessoal e social, será fomentado pelo exercício coordenado com os sons e o silêncio, entre atitudes percussivas, vocalizadas, improvisadas, no uso de jogos musicais, instrumentos, imitações corporais e nas inúmeras possibilidades de exploração criativa do professor. Cabe ao professor de dança, na sua caminhada pedagógica, construir amplas possibilidades sensoriais de apropriação rítmica. E essas possibilidades devem ser frutos de relações pessoais, coletivas e caracterizadas pela natureza social em que o grupo convive.

\section{REFERÊNCIAS}


BRASIL. Parâmetros Curriculares Nacionais. Educação Física. Brasília: MEC/SEF, v.7, 1997.

BRASIL. Parâmetros Curriculares Nacionais. Ensino Médio. Área de Linguagens, Códigos e suas Tecnologias. Brasília: Secretaria de Educação Média e Tecnológica/MEC, 1999.

CAMARGO, M. L. M. de. Música/Movimento: um universo em duas dimensões: aspectos técnicos e pedagógicos na educação física. Belo Horizonte: Villa Rica, 1994.

CAREGNATO, C. Estratégia métrica versus estratégia mnemônica: posições contrastantes ou complementares no ensino de ritmo? Revista da Associação Brasileira de Educação Musical, Porto Alegre, v. 19, n. 25, p.76-88, 2011.

CORDERO, O. H. G. A música, o ritmo e a Educação Física. Revista Científica da Faculdade de Educação e Meio Ambiente, São Paulo, v. 5, n. 2, p. 173-186, 2014.

GREENHEAD, K., HABRON, J. The touch of sound: Dalcroze Eurhythmics as a somatic practice. Journal of Dance \& Somatic Practices, Coventry, v. 7, n. 1, p. 93-112, 2015.

JUNQUEIRA, M. L. G., FORNARI, J. Psicomotricidade na Aprendizagem Musical. Núcleo Interdisciplinar de Comunicação Sonora - NICS Reports, São Paulo, n. 12, p. 24-31, 2015.

MONTEIRO, G. A., ARTAXO, I. Ritmo e movimento. São Paulo: Phorte, 2003.

MOTA, J. Rudolf Laban, a coreologia e os estudos coreológicos. Repertório, Salvador, Universidade Federal da Bahia, n. 18, p. 58-70, 2012.

SARAIVA, M. C. et al. Dança e seus elementos constituintes: uma experiência contemporânea. Práticas Corporais, Florianópolis, v. 3, p. 115-133, 2005.

TORTORA, G. J., DERRICKSON, B. Princípios de Anatomia e Fisiologia. 14. ed. Rio de Janeiro: Guanabara Koogan, 2016. 